\title{
Las empresas cooperativas ayudan a construir un mundo mejor. El caso centroamericano
}

\author{
Dra. Roxana Sánchez Boza'
}

Sumario: I. Antecedentes de los objetivos de desarrollo del milenio. II. Informe de cumplimiento. III. Papel de las cooperativas en la consecución de los ODM según las palabras del Secretario General de ONU: 3.1. Alianza Internacional de Cooperativas. 3.2. La confederación de cooperativas de ahorro y crédito COLAC. 3.3. Confederación de cooperativas de Centroamérica, el Caribe y Sudamérica. 3.4. Centro cooperativo sueco. IV. La plataforma constitucional y legal del cooperativismo, en la región centroamericana. Normativa a favor de las mujeres. 4.1. El caso de Costa Rica: un cooperativismo entusiasta y propositivo. 5. Conclusiones.

Resumen: En la Asamblea de la ONU, en la Cumbre del Milenio (2000), se redactaron y aprobaron por los Estados miembros los objetivos del milenio conocida como la Declaración del Milenio. De una revisión de los Objetivos de Desarrollo del Milenio, existen muchos de los elementos esenciales del cooperativismo. El artículo desbroza estos objetivos y los compara con los principios cooperativos, ahondando en el caso centroamericano.

Palabras clave: principios cooperativos, Organización de Naciones Unidas, objetivos de desarrollo del milenio, Centroamérica.

Abstract: At the United Nations Millennium Summit (2000), the Millennium Declaration was drawn up and approved by the member states at the General Assembly. A closer look at the Millennium Development Goals shows that many of the essential elements of cooperativism are included. This article clarifies these goals and compares them with the cooperative principles, studying the case of Central America in depth.

Key words: cooperative principles, United Nations Organization, Millennium Development Goals, Central America

1 Catedrática Universidad de Costa Rica y de la Universidad Latina, Presidenta Asociación costarricense de Derecho cooperativo, Miembro del Consejo Superior Notarial y de la Junta Administrativa del Registro Nacional, Vicepresidenta del Colegio de abogados y abogadas de Costa Rica, investigadora del Instituto de Investigaciones Jurídicas de la UCR. 


\section{Antecedentes de los objetivos de desarrollo del milenio}

Cinco años después de una exhaustiva revisión de los valores y principios del cooperativismo, promovida por la Alianza Internacional de Cooperativas ACl, en Manchester Inglaterra (1995) y en celebración de los cien años de existencia de este organismo cooperativo mundial, las Naciones Unidas proclaman Los objetivos de desarrollo del milenio, iniciado en el año 2000.

La vocación de respeto y cohesión que debe justificar la convivencia y desarrollo de la humanidad coinciden en muchos de los valores y principios del Cooperativismo, el cual surge como una herramienta de trabajo y progreso social gracias al esfuerzo de los Pioneros de Rochadle, Inglaterra, en el año 1943 —sin desmerecer la contribución de múltiples proyectos iniciados anteriormente sin éxito pero que contribuyeron a formular la doctrina cooperativa que hoy nos guía-.

En este año 2012, el Movimiento Cooperativo mundial tiene el deber-poder de llevar sobre sus hombros la distinción dada por las NACIONES UNIDAS cuando proclamo, a través de su Asamblea general, el reconocimiento a las cooperativas como un grupo de organizaciones que contribuyen a ofrecernos un mundo mejor.

El Cooperativismo como organización económico social se ha distinguido por sus valores y principios, revisados en 1995 para ser precisados y ampliados y ofrecer una guía más clara a los adeptos y adeptas de esta forma de vida.

De una revisión de los Objetivos de desarrollo del Milenio notamos que existen muchos de los elementos esenciales del cooperativismo, dentro de su texto, lo cual nos permite concluir preliminarmente que la atención en la forma organizacional de las cooperativas, es un excelente paradigma a seguir por otros grupos socio-económicos, como forma de cumplir con los objetivos propuestos.

En síntesis encontramos que en la Asamblea de la ONU, en la CUMBRE DEL MILENIO se redactaron y aprobaron por los Estados miembros los OBJETIVOS DEL MILENIO conocida como la Declaración del Milenio, los miembros de la ONU, reunidos en la Sede de las Naciones Unidas en Nueva York del 6 al 8 de septiembre de 2000, en los albores de un nuevo milenio, reafirmaron su fe en la Organización y su Carta como cimientos indispensables de un mundo más pacífico, más próspero y más justo y búsqueda de la mundialización como una fuerza positiva para todos los habitantes del mundo. ${ }^{2}$

2 Declaración de jefes de Estado. A/res/55/2s, Resolución aprobada por la Asamblea General, 55/2. Declaración del Milenio. 
Asimismo, reconocieron ciertos valores fundamentales que son esenciales para las relaciones internacionales en el siglo Xxl:

- La libertad. Los hombres y las mujeres tienen derecho a vivir su vida y a criar a sus hijos con dignidad y libres del hambre y del temor a la violencia, la opresión o la injusticia. La mejor forma de garantizar esos derechos es contar con gobiernos democráticos y participativos basados en la voluntad popular.

- La igualdad. No debe negarse a ninguna persona ni a ninguna nación la posibilidad de beneficiarse del desarrollo. Debe garantizarse la igualdad de derechos y oportunidades de hombres y mujeres.

- La solidaridad. Los problemas mundiales deben abordarse de manera tal que los costos y las cargas se distribuyan con justicia, conforme a los principios fundamentales de la equidad y la justicia social. Los que sufren, o los que menos se benefician, merecen la ayuda de los más beneficiados.

- La tolerancia. Los seres humanos se deben respetar mutuamente, en toda su diversidad de creencias, culturas e idiomas. No se deben temer ni reprimir las diferencias dentro de las sociedades ni entre éstas; antes bien, deben apreciarse como preciados bienes de la humanidad. Se debe promover activamente una cultura de paz y diálogo entre todas las civilizaciones.

- El respeto de la naturaleza. Es necesario actuar con prudencia en la gestión y ordenación de todas las especies vivas y todos los recursos naturales, conforme a los preceptos del desarrollo sostenible. Sólo así podremos conservar y transmitir a nuestros descendientes las inconmensurables riquezas que nos brinda la naturaleza. Es preciso modificar las actuales pautas insostenibles de producción y consumo en interés de nuestro bienestar futuro y en el de nuestros descendientes.

- Responsabilidad común. La responsabilidad de la gestión del desarrollo económico y social en el mundo, lo mismo que en lo que hace a las amenazas que pesan sobre la paz y la seguridad internacionales, debe ser compartida por las naciones del mundo y ejercerse multilateralmente. Por ser la organización más universal y más representativa de todo el mundo, las Naciones Unidas deben desempeñar un papel central a ese respecto.

Resulta que ya en el siglo XIX, y con antecedentes en otros proyectos de convivencia basada en la mutualidad, la solidaridad y la búsqueda de un mundo mejor, el Cooperativismo ya había adoptado el 
respeto a la igualdad, la solidaridad como forma de vida de sus miembros.

En concreto los miembros de la ONU redactaron los conocidos ODM, que se enuncian por número, sin que sea uno más importante que otro:

- Objetivos de desarrollo del milenio:

- Objetivo 1. Erradicar la pobreza extrema y el hambre.

- Objetivo 2. Lograr la enseñanza primaria universal.

- Objetivo 3. Promover la igualdad entre los sexos y la autonomía de la mujer.

- Objetivo 4. Reducir la mortalidad de los niños menores de 5 años.

- Objetivo 5. Mejorar la salud materna.

- Objetivo 6. Combatir el VIH/SIDA, el paludismo y otras enfermedades.

- Objetivo 7. Garantizar la sostenibilidad del medio ambiente.

- Objetivo 8. Fomentar una asociación mundial para el desarro\|lo.

Los Jefes de Estado que firmaron el 8 de setiembre de 2000 su compromiso también decidieron que al año 2015 velarían porque, para ese mismo año, los niños y niñas de todo el mundo puedan terminar un ciclo completo de enseñanza primaria y porque tanto las niñas como los niños tengan igual acceso a todos los niveles de la enseñanza.

También la promoción de la igualdad entre los sexos y la autonomía de la mujer como medios eficaces de combatir la pobreza, el hambre y las enfermedades y de estimular un desarrollo verdaderamente sostenible. Dentro de lo cual está la lucha contra todas las formas de violencia contra la mujer y aplicar la Convención sobre la eliminación de todas las formas de discriminación contra la mujer

Elaborar y aplicar estrategias que proporcionen a los jóvenes de todo el mundo la posibilidad real de encontrar un trabajo digno y productivo.

\section{Informe de cumplimiento}

Al año 2012 se elaboró un informe del cumplimiento de los ODM, dentro de lo cual encontramos que el objetivo de alcanzar la igualdad entre los géneros también sigue sin cumplirse, y se indica en ese In- 
forme que existen amplias consecuencias negativas, ya que alcanzar los Objetivos de Desarrollo del Milenio depende en gran medida del empoderamiento de la mujer y de un acceso de las mujeres, en condiciones de igualdad, a la educación, al trabajo, al cuidado de la salud y a la toma de decisiones. También debemos reconocer la desigualdad en los avances según los distintos países y regiones y las hondas diferencias que existen entre las poblaciones, en especial entre las de las áreas rurales y las de las urbanas.

En el Informe de cumplimiento de se manifiesta que alcanzar los Objetivos de Desarrollo del Milenio para 2015 es difícil pero no imposible. Depende mucho de que se cumpla el Objetivo 8: la alianza mundial para el desarrollo. Informe de 2012 NACIONES UNIDAS Nueva York, 2012.

\section{Papel de las cooperativas en la consecución de los ODM, según las palabras del Secretario General de ONU}

El plazo fijado de 2015 se acerca rápidamente. Las contribuciones de los gobiernos nacionales, la comunidad internacional, la sociedad civil y el sector privado deberán intensificarse para enfrentar el antiguo y persistente desafío de la desigualdad y para seguir luchando por la seguridad de los alimentos, la igualdad entre los géneros, la salud materna, el desarrollo rural, las mejoras de la infraestructura, la sostenibilidad del medio ambiente y la respuesta al cambio climático

Dirigir la atención a la contribución del COOPERATIVISMO al desarrollo del mundo basado en sus valores y principios es un gran acierto del Secretario de la ONU, Ban Ki-moon, pues indudablemente que este movimiento sin fronteras en el mundo, ha contribuido muchísimo en el desarrollo económico y social de los habitantes del mundo. El Cooperativismo ha ofrecido y formado a sus miembros en la organización democrática y participativa que es la cooperativa.

El Cooperativismo tiene como base la igualdad, la equidad, el respeto al ser humano, porque es una organización de personas físicas y no de capitales, cuando nos enfrentamos a este tipo de entes, en su base, la cooperativa.

Aunque no ha alcanzado en forma total muchas de las propuestas como son: el trato igual y equitativo entre géneros - sobre todo en países en desarrollo donde en el campo rural las mujeres están en desiguales condiciones de acceso a los medios de producción-, la incorporación de jóvenes - remozando sus principios en forma atractiva a las necesidades de este importante sector del mundo-, o incorporando la 
experiencia en forma integral de los antecesores, siempre y cuando éstos respeten el ascenso de la juventud a las instancias políticas y económicas de este Movimiento económico y social.

Ban Ki-moon, Secretario General de las Naciones Unidas ha publicitado mundialmente el excelente trabajo que realizan las cooperativas en el mundo:

Con su distintivo énfasis en los valores, las cooperativas han demostrado ser un modelo empresarial versátil y viable, que puede prosperar incluso en épocas difíciles. Su éxito ha contribuido a impedir que muchas familias y comunidades caigan en la pobreza.

La Asamblea General de las Naciones Unidas proclamó 2012 como el Año Internacional de las Cooperativas y se resaltó la contribución de las cooperativas al desarrollo económico y social, especialmente su impacto en la reducción de la pobreza, la creación de empleos y la integración social. Bajo el lema "Las empresas cooperativas ayudan a construir un mundo mejor», el Año Internacional de las Cooperativas tiene tres objetivos principales:

a) Crear mayor conciencia. Crear mayor conciencia del público sobre la contribución de las cooperativas al desarrollo económico y social, y al logro de los Objetivos de Desarrollo del Milenio.

b) Promover el crecimiento. Fomentar la constitución y el crecimiento de cooperativas, compuestas de personas e instituciones, para abordar sus necesidades económicas mutuas además de lograr una plena participación económica y social.

c) Establecer políticas adecuadas. Alentar a los gobiernos y organismos reguladores a implementar políticas, leyes y normativas que propicien la constitución y el crecimiento de las cooperativas.

Concluye esta declaración que al crear conciencia sobre las cooperativas, el Año contribuirá a fomentar el apoyo y desarrollo de empresas cooperativas compuestas de personas y sus comunidades.

Con esta acción el efecto será una mayor contribución del Cooperativismo a la consecución de los ODM, ahora en forma consciente porque ha sido reconocida su contribución a lograr un mundo mejor y se le incentiva a integrar su trabajo a esos objetivos.

Dentro del Cooperativismo existen entes mundiales como la Alianza Internacional Cooperativa y regionales, los cuales son múltiples y se organizan en torno a un sector o por región específica. En Centroamérica sobresalen la Confederación de Cooperativas de Centroamérica, El 
Caribe y Sudamérica (CCC-CA) y la Confederación de Cooperativas de ahorro y crédito COLAC.

También hay organismos internacionales dedicados al desarrollo del cooperativismo en países en desarrollo como el Centro cooperativo sueco o entes que se interesan en aspectos particulares de desarrollo del cooperativismo como:

\subsection{Alianza Internacional de Cooperativas ${ }^{3}$}

Es la organización que reúne a todas las cooperativas del mundo, en el año 1992 se regionalizó e inició una etapa importante en cuanto la atención del cooperativismo mundial de acuerdo con las necesidades de sus regiones, nace ACI-AMÉRICAS, la cual también tiene subdivisiones, este año se convocó a cooperativistas de la región, en Panamá, con la asistencia de mil delegados representantes de las cooperativas de América y acudieron los representantes de la ACI mundial.

Bajo el título del boletín de ese encuentro denominado «Las autoridades de la ACI-AMÉRICAS plantearon los principales retos de las cooperativas», la periodista Virginia Pérez Auza, Prensa ACI-Américas, recabó información el lunes 28 de mayo de 2012, donde el Presidente de ACI-AMÉRICAS, reflexionó en la II Cumbre Cooperativa de las Américas sobre los principales desafíos que enfrentan las cooperativas en el siglo XXI, porque todas las cooperativas tienen como un gran reto por delante, encontrar el equilibrio entre una buena gestiłón empresarial sin perder la doctrina cooperativa. "En general hay un desequilibrio. Sólo enfatizamos en la filosofía cooperativa y descuidamos la parte empresarial. Hay que generar buenos productos y buenos servicios junto a una buena gestión. Y eso es muy difícil de lograr, generalmente la balanza se inclina hacia un lado o hacia otro».

\subsection{La Confederación de Cooperativas de Ahorro y Crédito COLAC}

Como ente regional de América para integración y representación de las cooperativas de ahorro y crédito, más de intermediación finan-

3 «ACI Principales retos», http://www.aciamericas.coop/Cuales-son-los-principalesretos

4 También se puede ampliar la posición de la $\mathrm{ACl}$ en el documento «Cooperativas buscan dar un nuevo impulso», http://www.s21.com.gt/america/2012/05/29/cooperativasamerica-buscan-nuevo-impulso 
ciera, formuló sus compromisos ante la declaratoria de la ONU sobre el papel de las cooperativas, en su CARTA A LOS PRESIDENTES DE AMÉRICA LATINA, considerando la contribución de cooperativas del campo financiero, emitida en Panamá, 10 de abril de 2012, y haciendo resaltar la importancia de elaborar una agenda para dar conocer el modelo cooperativo como forjador de empresa y como estructurador de una democracia financiera y económica inclusiva, instrumentos reconocidos por los organismos multilaterales dentro de sus apoyos al fortalecimiento de gobiernos y países.

Los dirigentes de esta organización señores LUIS ÁNGEL PUIG Presidente de la Junta de Directores y EDUARDO YUNDA SÁNCHEZ, Gerente General han reafirmado la contribución de las cooperativas para lograr un mundo mejor, tal y como se manifiesta en las siguientes palabras insertas en la carta: " Los principios que inspiran el trabajo y los valores que soportan la gestión de las instituciones de naturaleza cooperativa, valorizan un pensamiento empresarial que ha sido exitoso, y que cada día se posiciona con mayor fuerza en todas las regiones y en todos los países, dejando huella en el aspecto económico y social. Ante todo, millones de personas en el mundo se sienten partícipes dentro de este modelo empresarial del desarrollo.»

En sus palabras resaltan muchos valores parte de la Declaración del Milenio: como igualdad, solidaridad, responsabilidad social como se observa en la lectura de otra parte de este importante comunicado a los Presidentes de América Latina:

Estas estructuras empresariales de autogestión y autoayuda son creadas por grupos de personas para solventar necesidades comunes $y$, al final mediante un trabajo colectivo, generan bienestar para toda la población y en su conjunto ayudan a formar el concepto de Nación y son soporte válido para sostener las democracias. Los cooperativistas se educan en la democracia y en los valores de los principios cooperativos, dentro de los cuales se destaca como esencial, la solidaridad. El conjunto del cooperativismo se convierte así en un valioso aliado para que el Estado pueda cumplir a cabalidad su función económica y social.

\subsection{Confederación de Cooperativas de Centroamérica, El Caribe y Sudamérica}

La Confederación creada inicialmente para atender la región centroamericana y El Caribe se ha extendido a Sudamérica, en este siglo. Tiene la atención de varios temas transversales que se acoplan con los 
valores planteados como base de los ODM e introducen el desarrollo de las cooperativas a partir del concepto de interdependencia en relación con otros entes privados y públicos en el tanto que el Estado los formamos todos los componentes de la sociedad.

La definición de los temas transversales asumida por la Confederación tiene el siguiente contenido a través de sus programas y proyectos y en los eventos sobre temas de especial sensibilidad y prioridad.

- Ambiente. La CCC-CA se plantea actuar como vehículo de concienciación y acción en su sector sobre la protección del ambiente, la naturaleza, recursos naturales y contra las vulnerabilidades ante desastres socio natural. Para ello participa activamente en la promoción y adopción de políticas nacionales y regionales de protección, promueve la coordinación de las estructuras de la sociedad civil regional a ese fin y desarrolla foros de discusión pública sobre la temática.

- Consideraciones étnicas y culturales. En sus acciones, la CCCCA toma en cuenta las particularidades, especificidades y necesidades de grupos poblacionales de la región centroamericana, caribeña y sudamericana, con características diferenciadas, como son los afro descendientes e indígenas, compartiendo y propulsando sus reivindicaciones especiales en el marco del sector cooperativo y en su proyección hacia las sociedades en general.

- Género. La CCC-CA promueve estrategias y acciones de participación equitativa de género (tanto hombres como mujeres) y el cumplimiento de políticas de igualdad de oportunidades; fortalece la participación, visibilidad y acción de la dirigencia regional de mujeres cooperativistas; asegura la capacidad estratégica del CRMC; fomenta la capacitación con becas; estimula el desarrollo de proyectos de mujeres; y respalda sus procesos de desarrollo de liderazgo.

- Juventud. La CCC-CA respalda el desarrollo de liderazgo de los jóvenes cooperativistas. Aunque cuentan con bajo apoyo externo, las actividades de y para jóvenes son de gran valor para garantizar el relevo del liderazgo dirigencial y profesional. A través del programa de becas especiales se propicia una participación mayor de jóvenes en los eventos.

- Tercera edad. La CCC-CA reconoce los aportes a la comunidad y al sector cooperativo de la veteranía y experiencia; y respeta y rescata las contribuciones de las generaciones ascendientes, por lo que respalda acciones de participación, protección, presencia y atención de las necesidades de los adultos mayores. 
La Confederación también tiene alianzas con los entes regionales y mundiales antes indicados, una de ellas es la particular existencia del Consejo Consultivo Nacional de Responsabilidad Social de Costa Rica, creado en julio del 2008, como una red/alianza de organizaciones públicas y privadas. Al Consejo consultivo se le considera pionero en Iberoamérica en el impulso de una nueva visión de la Responsabilidad Social. ${ }^{5}$

EI CCNRS trabaja basado en el concepto de la Responsabilidad Social como elemento de estrategia de competitividad y de sostenibilidad para las organizaciones públicas y privadas.

En palabras de Felix Cristiá, Director ejecutivo de la Confederación el nuevo entorno presenta nuevos desafíos para el liderazgo cooperativista, que hoy más que nunca debe prepararse para dar respuestas y soluciones, actuar con una nueva visión estratégica para enfrentar los retos y superar viejos esquemas que ya no sirven. ${ }^{6}$

\subsection{Centro Cooperativo Sueco ${ }^{7}$}

El Centro es una organización regional con sede en Costa Rica, con sus países contrapartes: Bolivia, Costa Rica, Nicaragua, El Salvador, Guatemala, Honduras y Paraguay.

Entre sus tareas se encuentran temas relacionados con derechos de las mujeres a la titularidad de la tierra, sus derechos económicos, sociales y culturales -aspectos étnicos de la mujeres indígenas y negras-; vivienda solidaria; organización de los miembros de las cooperativas; mercado justo, las cuales concuerdan en mucho con los ODM y se manifiestan como una importante contribución del Cooperativismo a su logro.

A modo de ejemplo, sin agotar la temática de acción de esta organización en cada uno de los países miembros, encontramos que en Honduras se inició, en el mes de marzo de 2011, la primera Escuela de Incidencia Política de las mujeres cooperativistas promovida por el Consejo Nacional de las Mujeres Cooperativistas de Honduras (CONAMUCOPHL). ${ }^{8}$

5 http://www.ccnrs.com/documentos/encadenamientos_productivos_RS/entrevista_ encadenamientos_socialmente_responsables.pdf

6 «El cooperativismo en el nuevo contexto» | ccc-ca.com, Copyright (C) 2010, Confederación de Cooperativas del Caribe, Centro y Suramérica Todos los derechos reservados.

7 http://www.sccportal.org/Default.aspx?ArealD=5

8 Revisar en «Honduras: escuela incidencias política», en http://www.sccportal.org/ Programas/Equidad-de-Genero/Archivo-noticias-equidad-de-g\%C3\%A9nero.aspx?M=N ews\&PID=1381\&NewsID=4269 
La primera Escuela de Incidencia Política en Honduras (EIP) como parte del Modelo de Incidencia Política creado exclusivamente y por primera vez en América Latina para las mujeres del sector cooperativista de la región por los Consejos Nacionales de Mujeres Cooperativistas de Honduras, Guatemala, El Salvador, Nicaragua, Costa Rica y Paraguay en el marco del Programa Regional de Equidad de Género del Centro Cooperativo Sueco.

La escuela tiene por objetivo fortalecer las capacidades de las mujeres lideresas en temas de Incidencia Política y el manejo de herramientas como los medios de comunicación, la Auditoría social entre otras. Todo con el fin de incidir en el sector cooperativo para lograr cambios en los marcos legales, esto es en ley de Cooperativas de Honduras, estatutos de las organizaciones cooperativas, formulación de políticas para la equidad de género y el fortalecimiento de las estructuras para la promoción de la equidad e igualdad entre hombres y mujeres del sector, como medidas afirmativas para el logro de la equidad de género. ${ }^{9}$

\section{La plataforma constitucional y legal del cooperativismo, en la región centroamericana. Normativa a favor de las mujeres}

En la región latinoamericana se encuentra la propuesta de la LEY MARCO PARA LAS COOPERATIVAS DE AMÉRICA LATINA, revisada y presentada al movimiento cooperativo latinoamericano y del Caribe en el año, 2009, por ACI-AMÉRICAS. De su texto se transcribe el artículo 21 dentro del cual se han incluido los derechos y deberes de los asociados y un aparte sobre la igualdad de género como avance en el reconocimiento de la igualdad y equidad de género que debe privar en el Cooperativismo Latinoamericano.

Artículo 21. Pueden ser socios las personas físicas mayores de edad y las personas jurídicas que requieran utilizar los servicios de la cooperativa, siempre que reúnan los requisitos establecidos por el estatuto. El ingreso es libre pero podrá ser supeditado a las condiciones derivadas del objeto social, sin discriminaciones de ninguna clase.

Igualdad de género

En todos los casos las cooperativas deben aceptar igual posibilidad de ingreso y reconocer idénticos derechos y obligaciones a todos los asociados y las asociadas sin distinción de género.

9 Entrevista realizada por Carolina MeLÉnDEZ, del Consejo Nacional de Mujeres Cooperativistas de Honduras (CONAMUCOPHL), publicada en página del CCS http://www. sccportal.org/Default.aspx?ArealD=5 
En la región centroamericana hay más acción que leyes para enmarcar la actividad generadora de mayores oportunidades de acceso a los medios de producción para las mujeres. En todos los países existe una ley de cooperativas y consideramos que se debe realizar la integración de esa normativa con las disposiciones constitucionales y legales para comprender el estado de situación de los derechos de la mujer.

En forma resumida se expone la actual situación de la legislación constitucional y cooperativa de cada país centroamericano.

La Constitución Política de Guatemala fue promulgada por el Decreto 1-85 de la Asamblea Nacional Constituyente, en relación con el principio de igualdad de las personas, en el artículo cuarto se hace mención de ambos sexos, se ubica en el TíTULO II denominado Derechos humanos.

\section{Capítulo I. Derechos individuales:}

Artículo 40. Libertad e igualdad «Libertad e Igualdad. En Guatemala todos los seres humanos son libres e iguales en dignidad y derechos. El hombre y la mujer cualquiera que sea su estado civil, tienen iguales oportunidades y responsabilidades. Ninguna persona puede ser sometida a servidumbre ni a otra condición que menoscabe su dignidad. Los seres humanos deben guardar conducta fraternal entre sí.

En ese título se establecen como obligaciones fundamentales del Estado el fomento y protección así como la creación de cooperativas proporcionándoles la ayuda técnica y financiera necesaria y más allá de las organizaciones cooperativas proteger la formación de capital, el ahorro y la inversión.

GUATEMALA se rige por la Ley General de Cooperativas, Decreto 82/78 (del 7 de diciembre de 1978, sigue el mismo esquema de definición de las cooperativas como entes económicos y-sociales, regidos por los principios cooperativos. Esa normativa junto con el Reglamento de Ley General de Cooperativas, Acuerdo Gubernativo n. ${ }^{\circ}$ ME 7/79 (del 17 de julio de 1979, integra el ordenamiento cooperativo guatemalteco.

EL marco legal de género en Guatemala encuentra un avance porque ya ese país ratificó la CEDAW desde 1982 (Decreto Ley 49-82), lo cual desde el punto de vista de su normativa constitucional ha tenido gran influencia en la redacción de normas que adecuan el ordenamiento jurídico de orden superior a los dictados de la Convención.

Por lo que consideramos que es una excelente base para integrar el orden jurídico de las cooperativas con el reconocimiento constitucio- 
nal de igualdad para ambos géneros y la aplicación de la CEDAW como norma superior que protege y garantiza los derechos de las mujeres.

LA CONSTITUCIÓN DE LA REPÚBLICA DE HONDURAS data de 1982, fue promulgada (Decreto n. ${ }^{\circ} 131$, del 11 de enero de 1982). No existe ninguna influencia presente en una actualización de los preceptos constitucionales en cuanto a los principios de igualdad ante la ley, en el TÍTULO III: DE LAS DECLARACIONES, DERECHOS Y GARANTÍAS.

En el CAPÍTULO I. DE LAS DECLARACIONES se reconoce mediante el artículo 59 que la persona humana es el fin supremo de la sociedad y del Estado. Todos tienen la obligación de respetarla y protegerla. Se establece la igualdad formal que ha venido caracterizando las constituciones de los siglos XIX y XX. Como vemos en el siguiente:

Artículo 60. Todos los hombres nacen libres e iguales en derechos. En Honduras no hay clases privilegiadas. Todos los hondureños son iguales ante la Ley.

Se declara punible toda discriminación por motivo de sexo, raza, clase y cualquier otra lesiva a la dignidad humana.

Este país se rige por la Ley de Cooperativas, que es el Decreto Legislativo 65/87 (del 30 de abril de 1987), y sobresale la definición del acto cooperativo -artículo 4- ligado al desarrollo de los cooperativistas en varios ámbitos de la vida del país, promoción del mejoramiento económico y social y del desarrollo personal de cada uno a tomando en cuenta su condición humanas y su formación individual y familiar —artículo 5-.

Honduras no ha ratificado la CEDAW y sin embargo participa en el PROGRAMA DE LA UNICEF denominado Programa regional latinoamericano de presupuestos con enfoque de género y de la Agenda económica de mujeres trabajado conjuntamente con el PNUD.

Tiene incorporada la LEY MARCO PARA COOPERATIVAS, que es un camino abierto para tener en cuenta los planteamientos de la misma respecto del enfoque de género. Y como antes mencionamos en Honduras se estableció la primera Escuela de Incidencia Política de las mujeres cooperativistas.

Costa Rica incorpora la CEDAW a su orden jurídico el 10 de diciembre de 1999, mediante ley aprobada por la Asamblea Legislativa y el PROCOLO FACULTATIVO el 20 de setiembre de 2001.

Lo anterior es importante porque la CEDAW forma parte del Derecho de ese país e ingresa con el mismo status de la normativa constitucional relacionada con los derechos humanos cuyos efectos tienen el 
reconocimiento de autoridad superior a las leyes —según artículo 7 de la Constitución Política-.

El principio de igualdad se mantiene redactado en la forma heredada de las constituciones liberales, artículo siguiente:

Artículo 33. Todo hombre es igual ante la ley y no podrá hacerse discriminación alguna contraria a la dignidad humana.

Ahora bien, gracias a una interesante labor de la Sala Constitucional creada en la última década del siglo pasado, se ha extendido la aplicación del lenguaje inclusivo, visto en forma tácita, y se ordena que donde la Constitución Política mencione hombre se debe entender que también se refiere a mujer.

En el ámbito electoral el CAPÍTULO II del Código Electora relativo al sufragio, reformado en forma sustantiva cuando se introdujo en el artículo 95, la garantía para las mujeres en la participación electoral del país, porque ese artículo establece que ley regula el ejercicio del sufragio de acuerdo con los siguientes principios:

8. Garantías para la designación de autoridades y candidatos de los partidos políticos, según los principios democráticos y sin discriminación por género. (Reforma Constitucional 7675 de 2 de julio 1997).

También fuera de la Constitución Política pero si aprovechando el desarrollo jurídico aportado por la Sala Constitucional al país, en materia de Derechos Humanos, la mujer ha logrado una mayor participación en directivas de instituciones autónomas, si bien en actual conformación de los entes cúpula del país no se refleja ninguna influencia. El voto de la Sala Constitucional n. ${ }^{\circ} 716-98$, de las 11:51 hrs, de 6 de febrero de 1998, señaló la obligatoriedad de la participación femenina en las juntas directivas:

(...) El Consejo de Gobierno estaba obligado, en cumplimiento del principio de igualdad, a postular y nombrar un número representativo de mujeres en la Junta Directiva de la Autoridad Reguladora de los Servicios Públicos, pues si bien tiene total discrecionalidad para determinar a quien nombra, en el entendido de que el postulante o postulado para el cargo cumpla losrequisitos de ley, esa discrecionalidad debe ser ejercida con apego al principio democrático y al principio de igualdad establecido en el artículo 33 constitucional y desarrollado, específicamente para el caso de la mujer, en la Convención sobre la eliminación de todas las formas de Discriminación contra la Mujer y en la Ley de Promoción de la Igualdad Social de la Mujer (CEDAW)... 
Existe una importante ley promulgada para regular la participación de la mujer en la Asamblea de trabajadores y trabajadoras del Banco Popular y de Desarrollo Comunal, así como en otras instancias político económicas de esa entidad financiera, por medio de la Ley n. ${ }^{\circ} 8322$ de 21 de octubre de 2002, denominada Ley de democratización de las instancias de decisión del Banco Popular y de Desarrollo Comunal.

Costa Rica tiene una Ley de asociaciones cooperativas y creación del Instituto nacional de fomento cooperativo que data del 22 de agosto de 1968, Ley ${ }^{\circ}{ }^{\circ} 4179$, reformada en diferentes ocasiones, pero que en el aspecto relacionado con la incorporación de las disposiciones de la CEDAW o la Ley marco para cooperativas de América no se han dado modificaciones, pese a la existencia de múltiples propuestas de reforma en la Asamblea Legislativa.

En El Salvador la Constitución Política fue promulgada el 15 de diciembre de 1983 por Decreto n. $^{\circ} 38$ y ese país ratificó la CEDAW el 4 de abril de 2001.

En el TÍTULO II denominado LOS DERECHOS Y GARANTÍAS FUNDAMENTALES DE LA PERSONA se encuentra el reconocimiento a la igualdad formal, artículo 3.

En un extenso artículo del TíTULO $V$ denominado ORDEN ECONÓMICO reconoce a las cooperativas y les da recursos junto con otras organizaciones y la posibilidad de acceder a la tierra como derecho de propiedad.

Ley General de Asociaciones Cooperativas de 25 de noviembre de 1979. Publicada el 29 de enero de 2004, presenta el mismo esquema del resto de países latinoamericanos donde no se ha dado la influencia de la CEDAW o la Ley marco para cooperativas de América.

Por parte de NICARAGUA encontramos que no ha ratificado CEDAW. En la Constitución Política de la República de Nicaragua promulgada el 9 de enero de 1987, se consagra la promoción y garantía de los avances de carácter social y político del país, para asegurar el bien común, asumiendo la tarea de promover el desarrollo humano de todos y cada uno de los nicaragüenses, protegiéndolos contra toda forma de explotación, discriminación y exclusión.

El artículo ibídem 5 establece los principios de la nación nicaragüense: la libertad; la justicia; el respeto a la dignidad de la persona humana; el pluralismo político, social y étnico; el reconocimiento a las distintas formas de propiedad; la libre cooperación internacional; y el respeto a la libre autodeterminación de los pueblos.

Este país se rige por la Ley de Cooperativas, que es el Decreto Legislativo 65/87 del 30 de abril de 1987 y sobresale la definición del acto cooperativo - artículo 4- ligado al desarrollo de los cooperativis- 
tas en varios ámbitos de la vida del país, promoción del mejoramiento económico y social y del desarrollo personal de cada uno a tomando en cuenta su condición humanas y su formación individual y familiar —artículo 5-.

En síntesis, en la región centroamericana, si la base del reconocimiento de los derechos de las mujeres, en condición de igualdad y equidad con los varones, se ubicaran en las constituciones políticas de cada país, se podría decir que el objetivo de los ODM, respecto de igualdad de géneros, se ha cumplido. Sabemos que esos derechos quedan en el ámbito formal y se deben dar muchos pasos y muy gigantes para lograr la igualdad y paridad sustantiva.

Hay que reconocer que las leyes cooperativas y el surgimiento de organizaciones femeninas dentro del cooperativismo, tienen como característica que ha sido más rápido el avance de la acción para lograr las metas de ofrecer más recursos de desarrollo a las mujeres, que la promulgación de leyes especiales.

\subsection{El caso de Costa Rica: un cooperativismo entusiasta y propositivo}

En el año 2010, el cooperativismo nacional se sumió en la búsqueda de mayores y mejores oportunidades para el sector cooperativo, por medio de los acuerdos de los foros en XII Congreso Cooperativo. ${ }^{10}$

En el Congreso participaron todos los sectores de producción y servicios así como los modelos de cooperativas: autogestionarias — trabajo asociado-, cogestionarías y demás cooperativas.

En el sector vivienda, a modo de ejemplo, se consideró importante profundizar las alianzas al interno de cooperativismo, para lograr una mejor integración cooperativa y también con el Estado, utilizando figuras jurídicas más accesibles como el condominio y el derecho de superficie para brindar soluciones de vivienda.

En atención a los sectores juventud, estudiantil y escolar en el Congreso se resaltó la importancia de un mejor conocimiento de las herramientas ofrecidas por la ley cooperativa y el ordenamiento jurídico en general para hacer realidad sus propuestas. ${ }^{11}$

Como parte de la necesidad de desarrollar esos grupos sociales, se propuso la creación de líneas de crédito revolutivas provenientes de las

10 En Foros cooperativos, ver http://www.conacoop.coop/biblioteca/forosCongresos. html

11 http://www.conacoop.coop/JUVENTUD.html 
cooperativas de los adultos y de otras fuentes para fortalecer los proyectos de las cooperativas escolares.

No hay duda que para construir un mundo mejor el Cooperativismo debe ofrecer mayores oportunidades, en palabras de la Dra. Roxana Sánchez Boza un mejor conocimiento de la legislación cooperativa puede permitir atender lo siguiente:

- Crear un fondo de avales que permita al sector cooperativo escolar acceder al crédito del fondo que existe en el INFOCOOP para cooperativas escolares y juveniles.

- Modificar el marco legal a efecto que el CONACOOP — Consejo nacional de cooperativas - pueda rendir avales para garantizar proyectos de cooperativas estudiantiles.

En el tema de ampliar la participación al interno del cooperativismo costarricense, el sector de ahorro y crédito busca la modificación de la actual legislación de cooperativas para ampliar la representatividad en el plenario del CONACOOP de este sector y un puesto en el INFOCOOP — Instituto nacional de fomento cooperativo-y ser tomados en cuenta para la designación de otros puestos de representación -en instituciones autónomas del Estado integradas por varios sectores de la Economía Social-. ${ }^{12}$

La deuda del cooperativismo costarricense con SECTOR MUJER se hizo evidente en las propuestas de este sector solicitó entre otros temas:

1. Que en la conformación de los órganos de dirección se cumpla con la ley de participación equitativa de la mujer. Lo anterior porque en el INFOCOOP el nombramiento de los directivos propuestos por el Consejo nacional de cooperativas no cumplen la cuota del $50 \%$ de representación femenina y masculina.

2. Que se busquen los mecanismos legales adecuados para que se cumpla la ley de paridad en los órganos de dirección. Este es un aspecto relacionado con las oportunidades de las mujeres para ser electas en las asambleas y su situación particular en cuanto la atención de múltiples tareas dentro del hogar, lo cual les impide asistir a sesiones de órganos sociales de las cooperativas que generalmente son en las noches o fines de semana.

12 XII Congreso Nacional Cooperativo. Foro jurídico: 27 de octubre de 2010. EDICOOP. Resumen de acuerdos de los foros de sectores con aspectos o efectos jurídicos. Elaborado por Dra. Roxana Sánchez Boza. Documento de circulación interna. 
3. La Asamblea de CONAMUJER, realizada el 19 de febrero del 2010, en dicha Asamblea se aprobó la presentación de una petitoria ante la Sala Constitucional para hacer efectiva la ley de paridad de género en todo el Movimiento Cooperativo.

También la organización del XII CONGRESO COOPERATIVO trabajo con ejes temáticos, uno de los más importantes fue el Eje temático-jurídico que conoció de varios temas:

1. Vigencia y actualidad de la LEY DE ASOCIACIONES COOPERATIVAS.

2. Representatividad en el Plenario del CONACOOP, máximo órgano de decisión del cooperativismo costarricense, que desde el año 1968 al presente se ha quedado atrasado en cuanto la participación de sectores y por ello se propuso que de acuerdo con el número de cooperativas por sector, giro económico, modelo de propiedad, juventud, género, ahorro y crédito autogestión, agrícola industrial se distribuyeran los puestos; también se propuso que se ampliara el plazo de elección de dos a cuatro años y previo a la elección establecer una comisión tripartita de acreditación para revisar la el número de miembros de cada cooperativa, en cada sector para garantizar la participación equitativa en la elección de miembros del Plenario.

En la conformación de las asambleas los y las representantes de cada una de las clases de cooperativas deberían respetar y aplicar la Ley de igualdad real de la mujer. El o la delegado (a) de cada cooperativa deberá ser un miembro del Consejo de Administración.»

\section{Conclusiones}

La atención dada en ese año por las Naciones Unidas al COOPERATIVISMO MUNDIAL es, sin lugar a dudas, un acierto por la contribución en un cumplimiento acelerado de la mayoría de los ODM sino de su totalidad.

La preparación del Cooperativismo en el desarrollo de la participación democrática de sus miembros; la existencia de un principio básico para el desarrollo de la persona humana como es el PRINCIPIO DE EDUCACIÓN Y FORMACIÓN -fundamento ideológico del Cooperativismo desde su nacimiento-; la búsqueda de dar más y mejores oportunidades a los diferentes sectores de cada país, como lo hacen los entes regionales con la especificidad de su acción de acuerdo con el país donde impulsan organizaciones cooperativas cuando ofrecen soluciones de vivienda, de aprovechamiento del agro o de acceso al crédito personal, 
son ejemplos del cumplimiento avanzado y la contribución de las cooperativas para lograr un mundo mejor.

Los tres objetivos base de la declaratoria del AÑO DE LAS COOPERATIVAS impulsado por la ONU, en este año 2012, se cumple con decisiones tan precisas y claras como las que tenemos de ejemplo del XII CONGRESO COOPERATIVO, en Costa Rica cuando entre las propuestas y compromisos se incluyen aspectos importantes vinculados con el Cooperativismo y el resto del país que se plasman en las siguientes acciones a ejecutar y a partir de la promoción del nivel básico de incubación del cooperativismo, en el cual nace una cooperativa como proyecto productivo y organización social, lo cual se da por voluntad de una o varias personas o por promoción del movimiento en algunas actividades económicas o sectores específicos, con lo cual se da el primer paso a la organización cooperativa y consecuentemente. Para alcanzar tales objetivos en el Congreso se propuso y aprobó en forma unánime, varias acciones de desarrollo del modelo cooperativo, de su integración interna así como con el resto de las actividades del país, con base en un desarrollo sostenible, como podemos observar en estos tres aspectos elegidos como paradigma del trabajo de las cooperativas en el mundo:

Propiciar el desarrollo del modelo cooperativo en las nuevas empresas que se formen en asocio con la niñez, juventud, las mujeres, las personas con necesidades especiales y otros sectores prioritarios de la sociedad costarricense.

Presentar el cooperativismo como en el motor de desarrollo desde: las comunidades, las escuelas, colegios e instituciones de educación superior los medios de divulgación y todas las actividades en que participen personas.

Procurar que las nuevas empresas en los sectores productivos nacionales nazcan con sello cooperativo para garantizar la sostenibilidad integralmente (económico, ambiental y sociocultural).

Promover la divulgación efectiva, permanente y sistemática de la filosofía e ideología cooperativa sostenible como modelo empresarial en el ámbito nacional.

Propuestas que sirven de base esencial para el desarrollo de los objetivos sétimo: que es garantizar la sostenibilidad del medio ambiente y octavo cuando promueve la asociación mundial para el desarrollo, pues las cooperativas en el mundo, constantemente se reúnen para buscar soluciones a grupos necesitados de soluciones conjuntas y relacionados con aspectos socio-económicos del quehacer de cada país. 
Este AÑO DE LAS COOPERATIVAS sirve para resaltar un trabajo centenario y constante de un grupo de ciudadanos de mundo comprometidos con los valores y principios del cooperativismo y muestra que es uno de los pocos movimientos en el mundo que desde un principio decidió tener valores y principios como guía del desarrollo de su organización.

El Cooperativismo ayuda a integrar personas físicas y organizaciones al interno de cada país, en cada región o continente del mundo, ahora será importante evaluar la declaratoria en cuanto medir los resultados del impulso y apoyo de las cooperativas por parte de Estados y organizaciones privadas en el mundo. 